University of Nebraska - Lincoln

DigitalCommons@University of Nebraska - Lincoln

1997

\title{
Evolutionary Implications of Meiotic Chromosome Behavior, Reproductive Biology, and Hybridization in 6X and 9X Cytotypes of Andropogon gerardii (Poaceae)
}

\author{
Guillermo A. Norrmann \\ Universidad Nacional de Nordeste \\ Camilo L. Quarín \\ Universidad Nacional de Nordeste \\ Kathleen H. Keeler \\ University of Nebraska - Lincoln, kkeeler1@unl.edu
}

Follow this and additional works at: https://digitalcommons.unl.edu/bioscifacpub

Part of the Botany Commons, Plant Biology Commons, and the Plant Breeding and Genetics Commons

Norrmann, Guillermo A.; Quarín, Camilo L.; and Keeler, Kathleen H., "Evolutionary Implications of Meiotic Chromosome Behavior, Reproductive Biology, and Hybridization in 6X and 9X Cytotypes of Andropogon gerardii (Poaceae)" (1997). Faculty Publications in the Biological Sciences. 295.

https://digitalcommons.unl.edu/bioscifacpub/295

This Article is brought to you for free and open access by the Papers in the Biological Sciences at DigitalCommons@University of Nebraska - Lincoln. It has been accepted for inclusion in Faculty Publications in the Biological Sciences by an authorized administrator of DigitalCommons@University of Nebraska - Lincoln. 


\title{
EVOLUTIONARY IMPLICATIONS OF MEIOTIC CHROMOSOME BEHAVIOR, REPRODUCTIVE BIOLOGY, AND HYBRIDIZATION IN $6 X$ AND $9 X$ CYTOTYPES OF Andropogon gerardi (PoACEAE) ${ }^{1}$
}

\author{
Guillermo A. Norrmann, ${ }^{2,3}$ Camilo L. Quarín, ${ }^{2}$ And Kathleen \\ H. KEELER ${ }^{4}$
}

${ }^{2}$ Instituto de Botánica del Nordeste, Universidad Nacional de Nordeste (UNNE), [3400] Corrientes, Argentina; and ${ }^{4}$ School of Biological Sciences, University of Nebraska-Lincoln, Lincoln, Nebraska 68588-0118

\begin{abstract}
Andropogon gerardii, big bluestem, has 60 and 90 chromosome cytotypes. Meiosis in the hexaploid was shown to be regular, although some secondary associations of bivalents form. Meiosis in the enneaploid $(2 n=9 x=90)$ is irregular, leading to most gametes having unbalanced chromosome complements. Both cytotypes show considerable self-incompatibility. Cytotypes crossed freely, forming a variety of fertile euploids and aneuploids. Indistinguishable exomorphology, intermixing in natural populations, and compatibility suggest that A. gerardii is best understood as a cytotypically complex single species.
\end{abstract}

Key words: Andropogon; big bluestem; cytogenetics; North American prairies; Poaceae; polyploidy.

Andropogon gerardii Vitman, big bluestem, was the dominant grass of the tallgrass prairie biome. Found from New England to Florida, west to lower elevations in the Rocky Mountains, within the tallgrass prairie, it was the dominant plant, forming up to $80 \%$ of total biomass (Weaver and Fitzpatrick, 1934; Weaver, 1959; Risser et al., 1980).

Until a decade ago, despite the fact that there were reports of different chromosome numbers in the literature (Church 1929, 1940; Nielsen, 1939; Gould, 1956, 1968b; Löve and Solbrig, 1964), the species was considered hexaploid (e.g., Gould, 1967, 1968a; Riley and Vogel, 1982). Because polyploidy is difficult to work with, breeders and genetic ecologists have either ignored $A$. gerardii or mass-selected without worrying about the detailed genetics. Consequently, the hexaploid cytotype was taken as representing the species. The hexaploid was characterized as a sexual outbreeder (Bennett, 1873; Law and Anderson, 1940).

In 1983 Keeler and Galbraith tested plants from natural populations using flow cytometry and found two levels of nuclear DNA. Chromosome counts showed the lower value to correspond to the hexaploid $(2 n=6 x=60)$ and the higher to correspond to an enneaploid cytotype ( $2 n$ $=9 x=90)$. Neither reproductive nor meiotic behavior has been described for the 90 chromosome cytotype, although it comprises up to $80 \%$ of the individuals in some populations (Keeler et al., 1987; Keeler, 1990, 1992).

The objectives of this research were to determine the basic elements of genetic reproduction and fertility in both hexaploids and enneaploids. One critical question

${ }^{1}$ Manuscript received 2 February 1996; revision accepted 4 September 1996.

${ }^{3}$ Author for correspondence.

The Argentine crew thanks CONICET and SECYT-UNNE funding. Technical assistance of Florencia Galdeano is gratefully acknowledged. Both labs thank Fundación Antorchas (Argentina) and the College of Agriculture of the University of Nebraska-Lincoln, who made possible the initiation of this international collaboration. this research addressed was whether the cytotypes constituted one species or two; for this reason the ability of the two cytotypes to cross and interbreed under controlled conditions was determined. Since the cytotypes are exomorphologically indistinguishable, we included interspecific hybridization with South American hexaploid Andropogon species for a precise determination of the chromosome number of the gametes of the 90 chromosome cytotype.

\section{MATERIALS AND METHODS}

Plants from wild populations (Table 1) were first grown in clay pots in the greenhouse and then transferred to soil at the experimental garden of Facultad de Ciencias Agrarias, UNNE, Corrientes, Argentina. The following techniques were used:

Cytology-Chromosome numbers were established from mitotic squashes of root tips that were collected from potted plants. Root tips were collected between 0800 and 1000 and pretreated for $2 \mathrm{~h}$ with bromonaphthalene at room temperature. Subsequently, the material was hydrolyzed with $1 \mathrm{~mol} / \mathrm{L} \mathrm{HCl}$ at $60^{\circ} \mathrm{C}$ for $10 \mathrm{~min}$ and stained with fuchsin; squashes were made in a drop of acetoorcein. To study meiosis, young inflorescences were fixed in Carnoy's solution and refrigerated in $70 \%$ ethanol. Pollen mother cells (PMC) were stained with acetocarmine. Smears were made permanent with Venetian turpentine.

Reproductive biology - Flowering was studied under greenhouse and outdoor common garden conditions for $4 \mathrm{yr}$. Inflorescences in different stages of development were used for the study of megasporogenesis and embryo sac development. They were fixed in FAA (18:1:1 70\% ethanol, glacial acetic acid and formaldehyde) and stored in $70 \%$ ethanol. Ovaries were dehydrated in a tertiary butyl alcohol series, embedded in paraffin, sectioned at $12-15 \mathrm{~mm}$, and stained with safranin-fast green.

Pollen germination on the stigma surface and tube growth following self-pollination as well as controlled pollination were determined by fluorescence microscopy. Pistils were dissected from spikelets $2-3 \mathrm{~h}$ after pollination, placed in $1 \mathrm{~mol} / \mathrm{L} \mathrm{NaOH}$ for $15 \mathrm{~min}$, transferred into $0.1 \%$ aniline blue solution for $15-30 \mathrm{~min}$, mounted on a glass slide with a drop of aniline blue. Penetration of the tubes up to the micropylar zone was recorded. 
TABLE 1. Sources of plant material. Additional ecological information about North American sites in Keeler (1990).

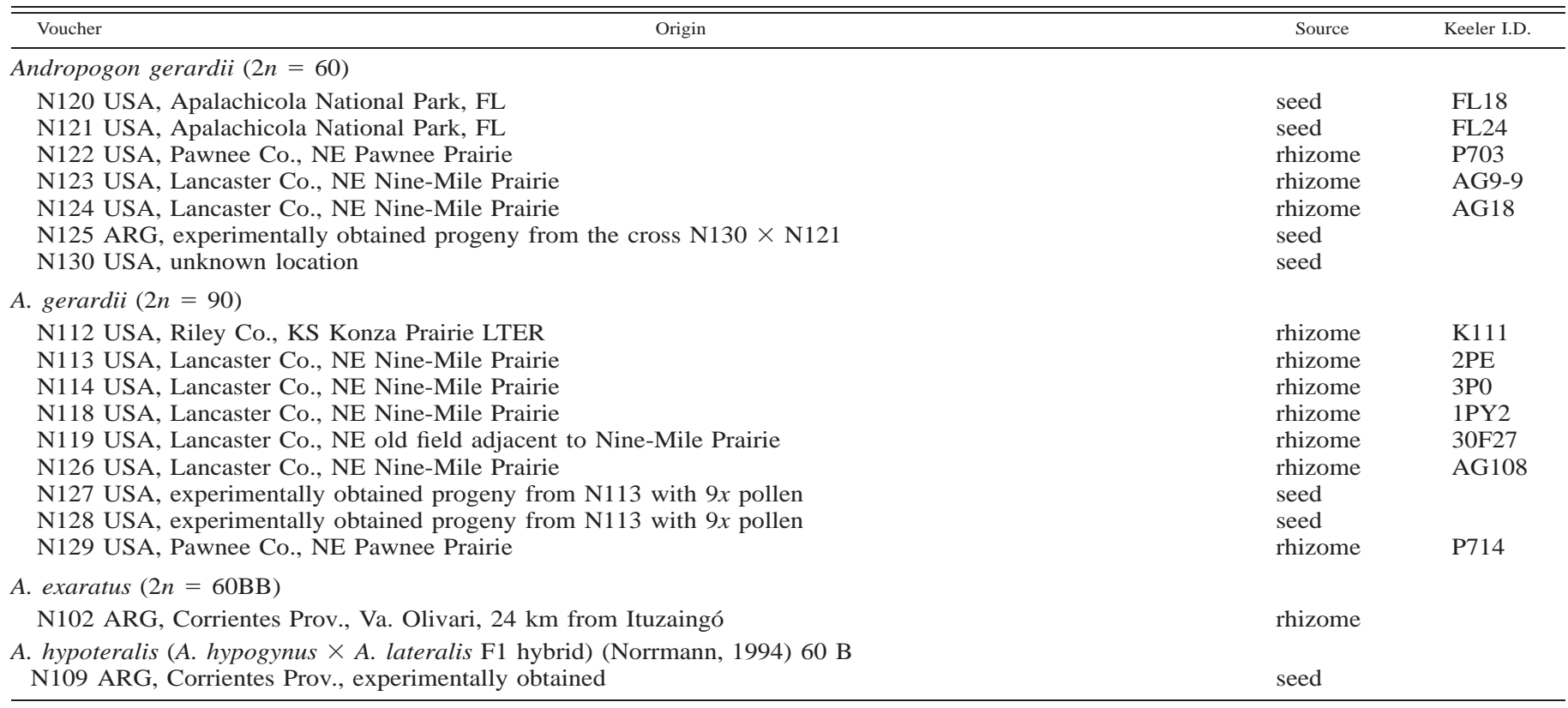

Seed set was determined under self- and open-pollinated conditions. Self-pollination was accomplished either by enclosing inflorescences in glassine bags or by isolating an individual plant. Plants of different accessions were placed close together for an estimation of seed set under open-pollinated conditions. Hand-assisted pollination was used in some cases, by collecting pollen in glassine bags and gently dusting over stigmata.

Survivorship - To estimate seedling survivorship, samples of progenies from either selfed or open-pollinated plants were grown for $3 \mathrm{yr}$. For each cross a random sample of seedlings was transplanted to determine percentage survival over time.

Crosses-Crosses intended to obtain intraspecific hybrids were performed between 1990 and 1993 using plants of the two cytotypes of $A$. gerardii. Inflorescences from both cytotypes were bagged the night before anthesis to prevent contamination and, the next morning, after anthesis, each plant was dusted with pollen of: (a) same cytotype but different genotype and (b) different genotypes of the other cytotype. Flowers were emasculated the 1st yr but later we found it unnecessary because of the self-incompatibility system present in all accessions (see below). Seed was harvested and sown in spring in the greenhouse. Seedlings were transplanted to a field nursery and hybrids were determined from the chromosome number of the plants obtained.

Interspecific crosses were performed using A. exaratus Hackel, a South American hexaploid species (Norrmann, 1985) and a fertile hybrid between A. hypogynus Hackel and A. lateralis Nees with $2 n=60$ +1 B (Norrmann, 1994), which we will refer to by the unofficial name A. hypoteralis. Since A. exaratus is andromonoecious (Norrmann and Quarín, 1991), as is A. gerardii, interspecific crosses were handled in a similar way as intraspecific crosses. Andropogon hypoteralis is monoecious with flowers that open at dawn (Norrmann, unpublished data) like both parents (Norrmann and Quarín, 1991) so we kept inflorescences of the pistilate parent bagged overnight and pollination was performed in the morning.

The data presented here differ in two ways from previously published work (Keeler et al., 1987; Keeler and Kwankin, 1989; Keeler, 1990, 1992). First, in the original work the higher DNA plants were reported as 80 chromosomes. We (GAN) recounted the slides upon which that was based, rechecked the plants for which the counts were made, and counted chromosomes on $>100$ additional "high DNA" plants, and conclude that high DNA plants are enneaploid with $2 n=90$. The original error can be attributed to the difficulty of visualizing and counting 90 chromosomes.

The second difference is that previously the low and high DNA values were given as $\approx 7.37(N=67, \mathrm{SD}=0.29)$ and $11.02(N=36$, $\mathrm{SD}=0.33$ ) pg DNA/nucleus, respectively. Those values were determined using mythramycin as the DNA stain (Keeler et al., 1987). For practical and theoretical reasons we changed to propidium iodide in 1992. With propidium iodide the mean values are $5.93(N=35$, $\mathrm{SD}=0.26)$ and $8.92(N=19, \mathrm{SD}=0.24)$, respectively. The ratio of nuclear DNA content between 90 and 60 chromosome cytotypes is unchanged: for mythramycin it is 1.496 , for propidium iodide 1.504 . The explanation of the different absolute value for the nuclear DNA contents of A. gerardii probably lies in the different DNA-binding methods of the two stains.

\section{RESULTS}

Mitosis-Plants from the seven low DNA accessions had $2 n=60$ chromosomes and all individuals from nine high DNA accessions were uniformly $2 n=90$ (Fig. 1).

Meiosis-Hexaploids had a regular meiosis, with 30 II in most cells of the five accessions scored, in agreement with previous reports (Riley and Vogel, 1982) (Table 2, Fig. 2). However, accessions N123 and N124 often showed secondary associations of bivalents (Fig. 3).

Meiosis in enneaploids was quite irregular (Table 2). In addition to univalents, other chromosome associations were scored: bivalents, trivalents, quadrivalents, pentavalents, and hexavalents (Fig. 4). The average number of associations per cell, from all individuals studied, was: $7.5 \mathrm{I}+16.1 \mathrm{II}+12.0 \mathrm{III}+2.4 \mathrm{IV}+0.3 \mathrm{~V}+0.5 \mathrm{VI}$ (based on 36 cells of 4 plants). Anaphase I usually showed 7-14 laggards (Fig. 5), often misdividing; there were also micronuclei in telophase I and II. As a con- 

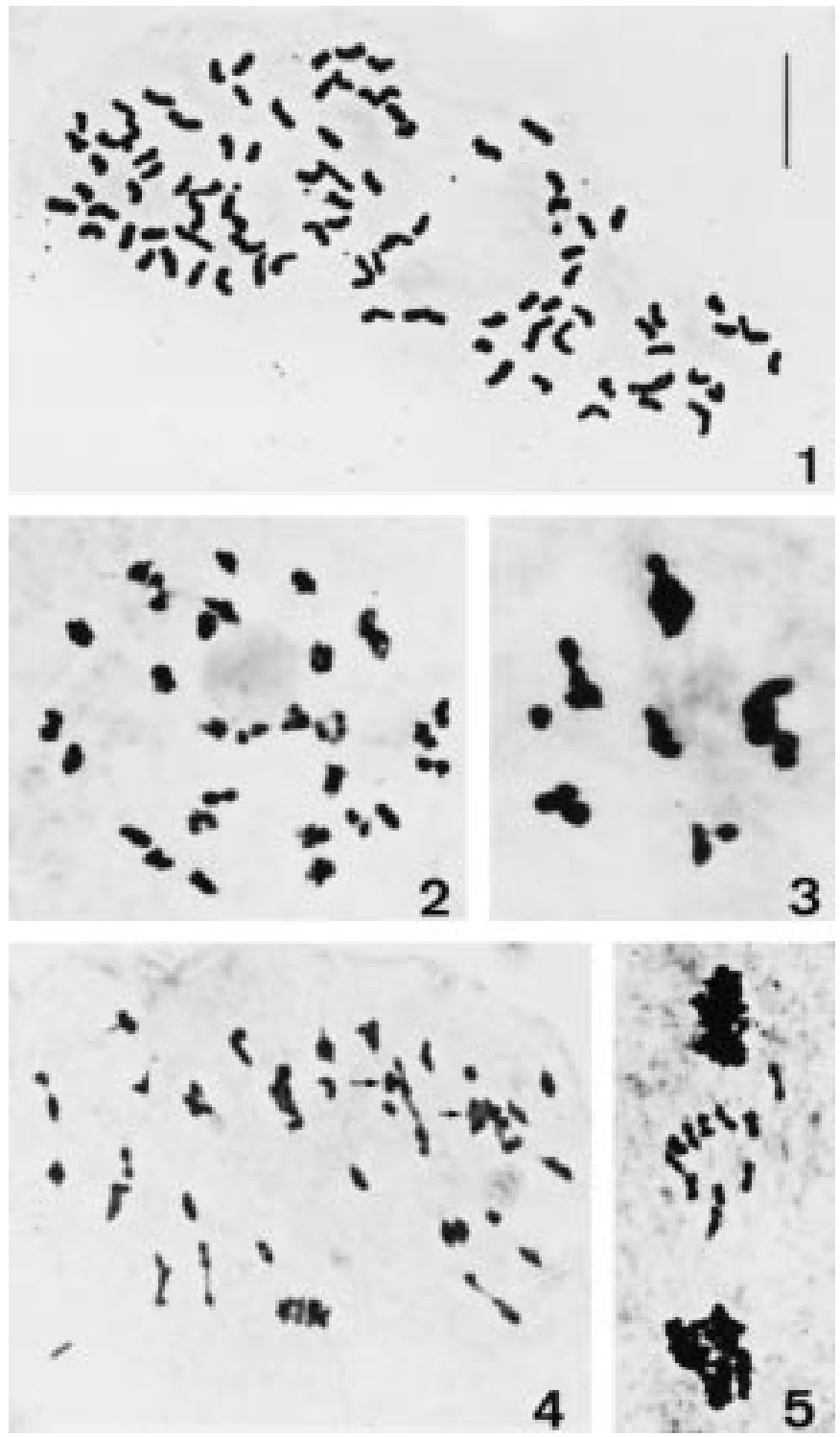

Figs. 1-5. Mitotic and meiotic chromosomes in Andropogon gerardii. 1. Mitotic metaphase with $2 n=90$ chromosomes in accession N112. 2. Diakinesis with 30 II in hexaploid N123. 3. Secondary meiotic associations at metaphase I in hexaploid N123. 4. Metaphase I in enneaploid N128 showing five univalents, 12 bivalents, eight trivalents, five quadrivalents, one pentavalent, and two hexavalents. Long arrow points to one trivalent overlapping a pentavalent. Short arrow points to one hexavalent close to a quadrivalent. 5. Telophase I with 11 laggards in enneaploid N126. Bar $=10 \mu \mathrm{m}$.

sequence of these irregularities, segregation was variable; in meiosis II it was possible to see prophases with chromosome arrays ranging from 32 to 50 . Notwithstanding these abnormalities, viable pollen was formed and pollen dispersal could be studied in all $9 x$ cytotypes.

Reproductive biology - Both cytotypes of A. gerardii are andromonoecious and flower early in the morning (0400-0700). Megasporogenesis and embryo sac development were studied in selected plants from the two cytotypes. In both, the process started when an archesporial
TABLE 2. Meiotic chromosome associations in Andropogon gerardii. Mean number of configurations per cell are given.

\begin{tabular}{lccccccccc}
\hline \hline Accession & $2 n$ & $\begin{array}{c}\text { No } \\
\text { cells }\end{array}$ & I & II & III & IV & V & VI & VIII \\
\hline N120 & 60 & 23 & & 30 & & & & & \\
N121 & 60 & 32 & & 30 & & & & & \\
N122 & 60 & 26 & & 30 & & & & & \\
N123 & 60 & 27 & & 30 & & & & & \\
N124 & 60 & 32 & & 30 & & & & & \\
N119 & 90 & 6 & 7.4 & 13.1 & 15 & 1.7 & 0.3 & 0.5 & 0 \\
Range & & & $4-9$ & $7-20$ & $11-18$ & $1-3$ & $0-1$ & $0-1$ & \\
N126 & 90 & 8 & 7.2 & 14.8 & 13.6 & 2.1 & 0.3 & 0.4 & 0 \\
Range & & & $3-12$ & $8-19$ & $12-18$ & 14 & $0-1$ & $0-2$ & \\
N128 & 90 & 15 & 7.2 & 19.5 & 8.5 & 3.1 & 0.4 & 0.7 & 0 \\
Range & & & $3-15$ & $12-25$ & $5-13$ & $1-9$ & $0-1$ & $0-2$ & \\
N129 & 90 & 7 & 8.6 & 12.7 & 15.1 & 1.7 & 0.3 & 0.4 & 0 \\
Range & & & $4-13$ & $5-19$ & $12-18$ & $0-5$ & $0-2$ & $0-2$ & \\
Average & 90 & 36 & 7.5 & 16.1 & 12.0 & 2.4 & 0.3 & 0.5 & 0 \\
\hline
\end{tabular}

cell enlarged and underwent meiosis to give a linear tetrad of megaspores.

In hexaploids, the three megaspores close to the micropyle degenerated and the chalazal one, through successive meiotic divisions, reached a short eight-nucleate stage. Afterwards, antipodals proliferated to create an embryo sac typical of sexually reproducing grasses. More than $96 \%$ of hexaploids had ovules with normal mature embryosacs (Table 3).

Megasporogenesis in enneaploids appeared normal and four megaspores were formed. In several ovaries, the embryo sacs developed as in hexaploids, thus giving rise to normal mature embryo sacs (Table 3 ). However, all other ovules showed deterioration and abortion of embryo sacs, either in early stages or up to the young eight-nucleate stage. The frequency of immature or aborted embryo sacs was so high in some genotypes as to practically eliminate the formation of seed (Table 3). Nevertheless most enneaploid cytotypes studied here showed some seed production, although there was much individual variation (Table 4 and below). The abortion of enneaploid gametes can be attributed to the irregularities observed in the meiotic processes in which they originated (above).

Pollen-pistil interactions and fertility-In controlled self-pollination of hexaploids, the pollen germinated shortly after contacting the stigmata. Following germination, the pollen tubes immediately began elongating

TABLE 3. Megasporogenesis and embryo sac development. Sample size in all cases exceeds 100 ovaries scored per plant.

\begin{tabular}{cccc}
\hline \hline & & \multicolumn{2}{c}{ Type of development $(\%)$} \\
\cline { 3 - 4 } Accession & $2 n$ & Complete & Aborted/immature \\
\hline N120 & 60 & 98 & 2 \\
N121 & 60 & 99 & 1 \\
N122 & 60 & 96 & 4 \\
N130 & 60 & 100 & 0 \\
N112 & 90 & 2 & 98 \\
N113 & 90 & 38 & 62 \\
N114 & 90 & 28 & 72 \\
N118 & 90 & 24 & 76 \\
N126 & 90 & 1 & 99 \\
N127 & 90 & 15 & 85 \\
\hline
\end{tabular}


TABLE 4. Percentage seed set and survivorship under different pollinating conditions. Seedling rates calculated based on number of germinated seedlings. Survivorship estimated 3 yr after germination

\begin{tabular}{ccccccc}
\hline \hline & & \multicolumn{2}{c}{ Self-pollination } & & \multicolumn{2}{c}{ Open-pollination } \\
\cline { 3 - 4 } \cline { 6 - 7 } Accession & $2 n$ & Seed set & Survival & & Seed set & Survival \\
\hline N120 & 60 & 0.9 & 0 & & 59 & no data \\
N121 & 60 & 0 & 0 & & 68 & no data \\
N122 & 60 & 6 & 0 & & 62 & 95 \\
N125 & 60 & 0.2 & 0 & & 73 & 100 \\
N130 & 60 & 4 & 0 & & 49 & no data \\
N112 & 90 & 0 & 0 & & 0.01 & 5 \\
N113 & 90 & 0 & 0 & & 29 & 52 \\
N114 & 90 & 0 & 0 & & 3 & 43 \\
N118 & 90 & 0 & 0 & & 12 & 73 \\
N126 & 90 & 0 & 0 & & 0.01 & 15 \\
N127 & 90 & 0 & 0 & & 14 & 65 \\
\hline
\end{tabular}

and penetrated the stigma papillae. In one accession (N121), tubes grew a short distance down the branches, and only a few reached the central axis of the stigma, where all of them were arrested. This accession never set seed when selfed (Table 4). In other hexaploid genotypes, although most tubes were arrested at stigma-style level as in N121, 1-2 tubes would reach the ovaries and discharge into the micropile (fewer than $10 \%$ of the ovaries observed). Seed set after selfing consequently was 0.2$6 \%$ (Table 4). In contrast, when another hexaploid genotype was employed as pollen source, tubes grew through stigma, style, and ovaries, penetrating the micropyle without any barrier. More than $90 \%$ of the pistils had pollen tubes into the micropyle $2 \mathrm{~h}$ after pollination, and seed set under these conditions was always greater than $49 \%$ (Table 4). The low seed set after self-pollination was caused primarily by the failure of pollen tubes to penetrate and grow into the style. In addition, survival of self-pollinated progenies was poor: most seedlings died within the 1st mo and none lasted more than one growing season (Table 4). Both facts point to an outcrossing system. Law and Anderson (1940) were the first to carefully report loss of vigor and low seed set after selfing. Our results are in agreement with theirs, and selfincompatibility explains the low seed set after selfing in both cases. In addition, these results showed us that emasculation was unnecessary before crosses.

Pollen-pistil observations on selfed enneaploids revealed that some pollen germinated and penetrated the stigma. Afterwards, all pollen tubes were arrested at the stigma-style level. We forced geitonogamy to ensure higher amounts of germinating pollen and the same self- incompatibility reaction was observed. On the other hand, when foreign pollen was provided (either from $6 x$ other plants or from $9 x$ plants), pollen would germinate and grow through stigma, style, and ovary, reaching the micropyle in $<2 \mathrm{~h}$. Our enneaploids never set seed upon selfing and these results indicate that the self-incompatibility system is maintained at the enneaploid level in the plants we studied. Consistent with the pollination observations, all enneaploid genotypes tested set some seed when another plant, whether another enneaploid or a hexaploid, provided pollen. Seed-setting percentages in enneaploids were much lower than in hexaploids (Table 4). However, large plants may produce $>100 \mathrm{~g}$ of achenes in a good year, so the interpretation of different percentages of seed is not straightforward, because enneaploids are often larger diameter plants than hexaploids (Keeler, unpublished data). Low fertility in enneaploids can be understood as a result of maintenance of the self-incompatibility system coupled with a variable amount of aborted and immature embryo sacs and unbalanced pollen grains due to meiotic irregularities.

Crosses and hybrids-We crossed 14852 spikelets from both cytotypes and obtained 112 hybrids in different combinations (Table 5). We also obtained six interspecific hybrids using $9 x$ gerardii cytotypes and South American species of Andropogon.

$6 x \times 6 x$ crosses - These crosses were used as controls and as a source of material for analysis of the reproductive biology. From 98 spikelets of N121 $\times$ N130, we obtained 46 plants, all of which were $2 n=60$ (Table 5).

$6 x$ (female) $\times 9 x$ (male) crosses-We crossed seven different combinations of 1078 spikelets and succeeded in four of them. Effective hybridization was confirmed by chromosome number, since progenies were morphologically indistinguishable from either parent.

Chromosome numbers in progenies were $2 n=68$ to $2 n=80$ (Figs. 6-8). From 198 crossed spikelets of N122 $\times \mathrm{N} 114$, we obtained three hybrids with $2 n=71$ (one plant), $2 n=76$ (one) and $2 n=80$ (one). We crossed 92 spikelets of N122 $\times$ N126 and obtained 19 hybrids with $2 n=68$ (one), 70 (two), 72 (two), 73 (three), 74 (six), 75 (two), 76 (one) and 80 (two). The cross N122 $\times$ N118 involved 90 spikelets and we obtained one hybrid with $2 n=76$ chromosomes, 252 spikelets from the cross N121 $\times$ N127 gave only one hybrid with $2 n=68$ chromosomes. Crosses of a total of 446 spikelets in N121 $\times$ $\mathrm{N} 126$ and of N121 $\times \mathrm{N} 128$ were all sterile. Of the hy-

TABLE 5. Crosses and hybrids.

\begin{tabular}{|c|c|c|c|c|c|c|c|c|c|c|c|}
\hline \multirow[b]{2}{*}{ Source } & \multirow{2}{*}{$\begin{array}{l}\text { Successful/ } \\
\text { total }\end{array}$} & \multirow{2}{*}{$\begin{array}{l}\text { Number of } \\
\text { crosses }\end{array}$} & \multirow{2}{*}{$\begin{array}{l}\text { Number of } \\
\text { hybrids }\end{array}$} & \multicolumn{8}{|c|}{ Chromosome numbers ${ }^{\mathrm{a}}$} \\
\hline & & & & 60 & $61-69$ & 70 & $71-79$ & 80 & $81-89$ & 90 & $91-99$ \\
\hline $6 x \times 6 x$ & $1 / 1$ & 98 & 46 & 46 & & & & & & & \\
\hline $6 x \times 9 x$ & $4 / 7$ & 1078 & 24 & 0 & 2 & 2 & 17 & 3 & 0 & 0 & 0 \\
\hline $9 x \times 6 x$ & $3 / 9$ & 1176 & 23 & & & 8 & 13 & 2 & & & \\
\hline $9 x \times 9 x$ & $3 / 4$ & 12500 & 19 & & & & & & 10 & 3 & 6 \\
\hline $9 x \times$ A. exaratus & $2 / 2$ & 136 & 3 & & & 2 & 1 & & & & \\
\hline A. hypoteralis $\times 9 x$ & $1 / 1$ & 98 & 3 & & & 1 & 2 & & & & \\
\hline
\end{tabular}

a $\mathrm{B}$ chromosomes are excluded from this table. 


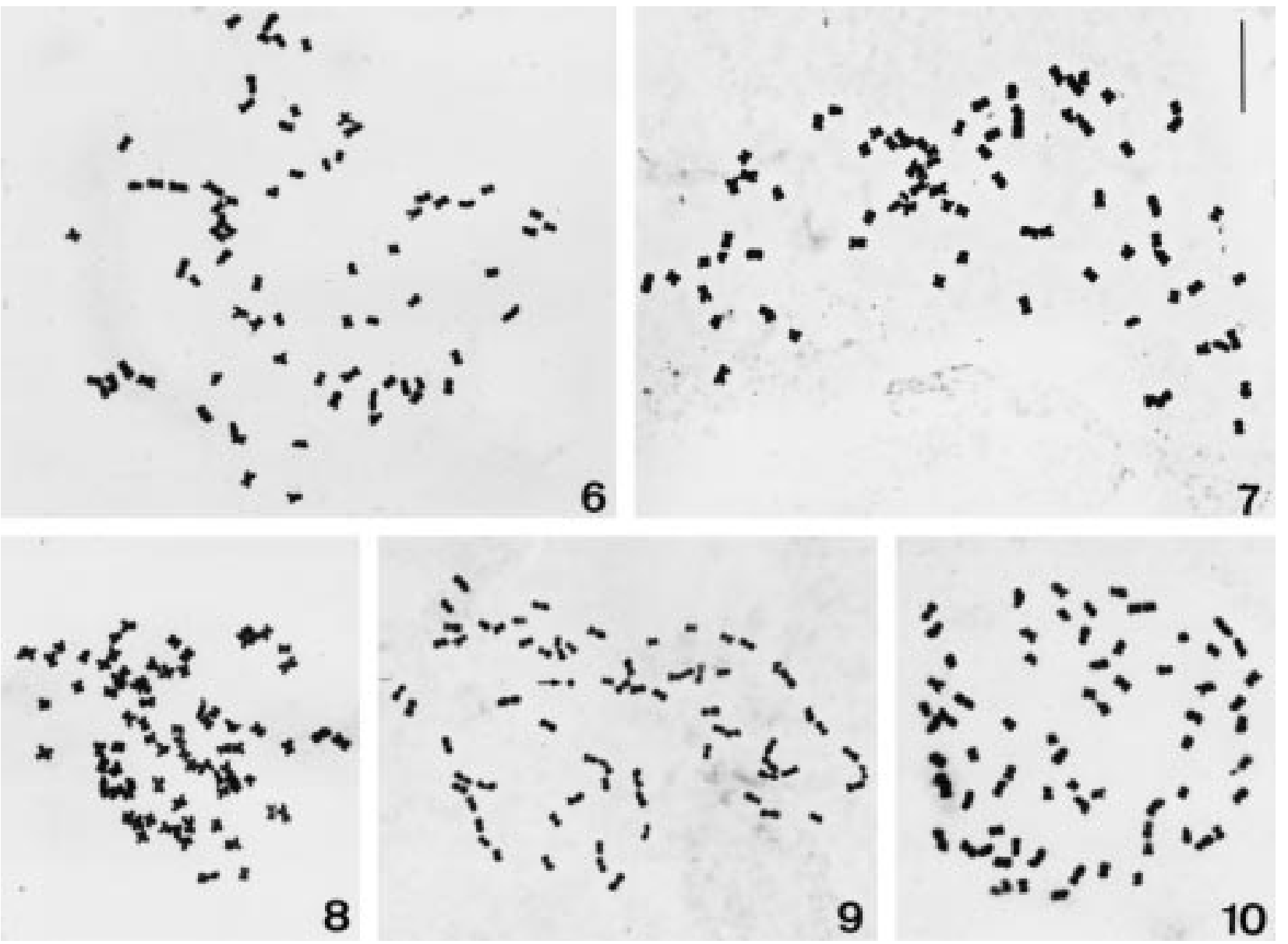

Figs. 6-10. Mitotic chromosomes in intra- and interspecific hybrids of Andropogon gerardii. 6-8. Intraspecifiic hybrids from hexaploid $\times$ enneaploid crosses . 6. $2 n=72$ chromosomes. 7. $2 n=75$ chromosomes. 8. $2 n=76$ chromosomes. 9-10. Interspecific hybrids. 9. Enneaploid $A$. gerardii $\mathrm{N} 114 \times$ A. exaratus $\mathrm{N} 102$ hybrid with $2 n=70+\mathrm{B}$ (arrow). 10. A. hypoteralis $\mathrm{N} 109 \times$ enneaploid $A$. gerardii $\mathrm{N} 113$ hybrid with $2 n=$ 71. $\mathrm{Bar}=10 \mu \mathrm{m}$.

brids, $92 \%$ have chromosome numbers between $2 n=70$ and $2 n=80$ and aneuploids (any number differing from $60,70,80$, and 90) comprise the highest percentage of descendants.

By assuming that hexaploid gametes were all 30 chromosomes, we infer that chromosome numbers of viable male gametes in $9 x$ plants were $38-50$.

$9 x$ (female) $\times 6 x$ (male) crosses -We tried nine combinations ( 1176 crossed spikelets) and succeeded in three of them, obtaining 23 hybrids. The cross N113 $\times$ N122 involved 74 spikelets that gave rise to 19 hybrids with the following chromosome numbers: $2 n=70$ (seven), 72 (two), 73, 74 (two), 75 (three), 76, 78, and 80 (two). One hundred thirty-four crossed spikelets of N128 $\times$ N121 gave only one hybrid (70 chromosomes). The cross N127 $\times$ N122 gave three hybrids $(2 n=72,75$, and 76) from 140 crossed spikelets. Unsuccessful crosses (828 spikelets in six combinations) mostly involved accessions N112 and N126, which were the enneaploid plants with the highest degree of female sterility. In all these crosses, $100 \%$ of the hybrids had $2 n=70$ to $2 n=80$ chromosomes. Once again, most progeny were aneuploids, though the most common number was $2 n=70$ (euploid, eight plants) followed by $2 n=75$ (aneuploid, four plants).

Since the hexaploid male parent probably produced normal $n=30$ gametes, the chromosome numbers of female gametes ranged from 40 to 50 .

$9 x \times 9 x$ crosses - Since we were aware of meiotic irregularities in the enneaploid plants, to assure good pollination in these crosses we used large amounts of mixed pollen from enneaploid plants on 12500 spikelets of four plants. Harvested spikelets were sown, giving rise to 169 seedlings presumed to be hybrids. We counted chromosomes in random samples of the progeny of each plant, with the following results: N112s were $2 n=82,90$ (two plants), and 92. N118s were $2 n=84,85,87,88$ (two), and 95 . N113s progeny were $82,83,85,88,90,91,94$, and 95 (two). We could not obtain any progeny from N126.

Interspecific hybrids - Interspecific hybridizations with South American hexaploid Andropogon species had the virtue that the other species were different enough morphologically from A. gerardii to allow recognition of hybrids by morphological features. Results are summarized 
in Table 5 (B chromosomes are excluded, since they are irrelevant in this context). Two A. gerardii plants were used as seed parents with one pollen donor of $A$. exaratus $(2 n=60+2 \mathrm{~B}$; Norrmann, 1985). We obtained one hybrid ( $2 n=70+\mathrm{B}$, Fig 9$)$ from 52 spikelets of $A$. gerardii $\mathrm{N} 114$ and two hybrids $(70+\mathrm{B}$ and $77+2 \mathrm{~B})$ from 84 spikelets of N118.

Using A. hypoteralis as the maternal parent and enneaploid Andropogon gerardii N113 as the pollen parent we obtained three hybrids $(2 n=70$ and 71 [two], Fig. 10) from 98 crossed spikelets.

Thus the chromosome numbers of interspecific hybrids matched nicely with previously described $6 x \times 9 x$ intraspecific crosses and confirm that chromosome numbers in other progenies were the result of effective crossing.

Survivorship of the hybrids - After three years, several of our $6 x \times 9 x, 9 x \times 6 x$ and $9 x \times 9 x$ intraspecific hybrids as well as $6 x \times 9 x$ and $9 x \times 6 x$ interspecific hybrids are no longer alive; to date we can find no pattern in their survivorship related to euploidy/ aneuploidy or to chromosome number.

\section{DISCUSSION}

Despite its ecological and economic importance, $A$. gerardii has received little genetic and reproductive analysis. Although chromosomal variation was recognized long ago (Gould, 1968b), only the most common hexaploid cytotype has been described chromosomally (Riley and Vogel, 1982).

The present work describes meiotic and reproductive behavior in $6 x$ and $9 x$ cytotypes, and the viability of their hybrids. The hexaploid has normal meiosis, while meiosis in the enneaploid is irregular, resulting in many defective gametes. Most of the genetic loss seen in A. gerardii results from poor meiotic behavior in the enneaploid cytotype: it is self-incompatible and has low fitness when outcrossed, whether crossing within or between cytotypes. While its presence lowers the seed set of the hexaploid, our data are not inconsistent with the model that the enneaploid is more fit crossing with the hexaploid than with other enneaploids. Thus we have a chromosomal complex for which the evolutionary stability will depend upon the relative fitness of within- and betweencytotype crosses. Since our data also indicate strong genotype-specific effects, in addition to cytotypic effects (Table 5), these fitnesses may be very difficult to identify and may not be stable in space and time.

Based on the present data, the most feasible explanation for the enneaploids' origin is through a secondary process of polyploidy from the hexaploid cytotypes. The precise mode by which this polyploidization occurs is not known, but the most probable explanation is through the nonreduction of gametes (e.g., Stebbins, 1971; de Wet, 1980). While we have been alert for it, so far we have not seen spontaneous nonreduction (Table 5; G.A. Norrmann, unpublished data; K.H. Keeler, unpublished data).

The pairing pattern seen in the hexaploids at meiosis suggests a purely alloploid origin (Table 2). Nevertheless, some secondary associations found in them point to ancestral homologies. This is supported by the meiotic configurations found in enneaploids. If $9 x$ plants originated merely by chromosome increase from a strict allohexaploid through an unreduced gamete, we would expect trivalents to be the highest multivalent association at meiotic metaphase. This was not the case in any studied $9 x$ plant (Table 2): whether collected as rhizomes or seeds, meiotic figures always included an important component of tetravalents, pentavalents, and even hexavalents, as well as bivalents, trivalents, and univalents. The conspicuous presence of associations higher than trivalents is generally better explained in terms of ancient homologies rather than reciprocal translocations. If this is the case, the genomes involved in the hexaploids' constitution would have some relictual or hidden homology that is expressed at the enneaploid level. A continuing hybridization program is intended to help clarify these relationships.

All cytotypes reproduce sexually. This research also shows that hexaploids are essentially outcrossing, in agreement with previous treatments (Law and Anderson, 1940; Peters and Newell, 1961). A self-incompatibility system coupled with inbreeding depression after selfing will readily account for the low degree of seed set upon selfing.

Our enneaploids never set seed under isolation, due apparently to (1) the persistence of the self-incompatibility system present in hexaploids; (2) poor-quality enneaploid pollen; and (3) low female fertility. The latter two are a result of an irregular meiotic process. However, all plants studied have male fertility and many of them also have female fertility, both types of gametes giving rise to embryos and seedlings with variable chromosome numbers. The percentages of female sterility are apparently related to the degree of meiotic disturbances in each enneaploid cytotype.

When hexaploids were crossed to other hexaploids, progenies were uniformly hexaploid. When hexaploids were crossed to enneaploids or vice versa, a variable array of chromosome numbers was found in progenies, ranging from $2 n=68-80$ chromosomes. This observation was confirmed through interspecific crossing experiments where successful hybridization could be established from the morphological characters of the offspring. Variability in chromosome number among the hybrids is due to irregular meiotic chromosome segregation in the enneaploid cytotypes of $A$. gerardii.

When enneaploids are crossed with each other, they produce an array of cytotypes, as would be predicted from their meiotic irregularities. An interesting aspect of this is that chromosome numbers higher than the parents were occasionally produced, as well as the parental $2 n=$ 90 (Table 5).

One finding that seemed remarkable was the ease with which $6 x$ and $9 x$ cytotypes interbreed. This reinforces the hypothesis that the enneaploids originated from the hexaploids. Furthermore, intraspecific hybrids are exomorphologically indistinguishable from each parent and characteristics such as stigma color, blade form, plant shape, general vigor, and differential survivorship show variation not correlated with cytotype (G. A. Norrmann and C. L. Quarín, unpublished data). None of some 12 electrophoretic systems and $>60$ bands observed distinguish the cytotypes (K.H. Keeler, L.S. Vescio, and C.F. Williams, unpublished data). Height and overall plant size, 
although extremely plastic, are consistently associated with cytotype (K.H. Keeler unpublished data): enneaploids are bigger. Mean cell size is probably also larger in enneaploids, as indicated by slightly greater stomate diameter (K.H. Keeler, unpublished data), results that follow logically from the greater number of chromosomes in the nucleus. Thus, the few differences between the cytotypes are attributable to allometric effects of increased ploidy level.

Despite the genetic load conferred on a population by the presence of two cytotypes, our interpretation is a single species with intraspecific polyploid variation. This is awkward but simpler than defining two exomorphologically indistinguishable and interfertile cytotypes as separate species. The evolutionary situation (incipient speciation?) is unclear at this time as well. Other well-studied examples of intraspecific polyploidy include Holcus mollis (Jones, 1958), Dactylis glomerata (Lumaret, 1988), Panicum virgatum (Nielsen, 1944), Paspalum (Norrmann, Quarín, and Burson, 1989) and Claytonia virginica (Lewis, Suda, and MacBryde, 1967). The situation in $A$. gerardii is also consistent with widespread polyploid variation found in the grasses of North American prairies (Keeler and Kwankin, 1989).

Natural populations of $A$. gerardii in North American prairies often have approximately equal numbers of hexaploids and enneaploids (Keeler, 1990, 1992). Since hand-crosses generated abundant aneuploids, which are rare in native prairies, the way this system functions in nature remains unclear. One possibility is that aneuploids are produced but do not survive to reach large sizes and so are undersampled. There are complex biases involved in sampling a phenotypically plastic dominant grass in a grassland; for example, one tendency is to sample larger, flowering individuals because their identity is unambiguous. Our (KHK) field collections still begin with up to $15 \%$ of the sampled plants being grasses that were mistaken for $A$. gerardii. Current detailed mapping studies in progress on native prairie populations address the apparent absence of aneuploids.

Despite or because of intraspecific polyploidy, A. gerardii was an ecosystem dominant across central North America, with a range from the Atlantic Coast to over $2000 \mathrm{~m}$ in the Rocky Mountain foothills. It is currently thriving as a roadside species throughout much of its former range. Thus, as is the case for Dactylis glomerata (Lumaret, 1988; Lumaret and Barrientos, 1990) and Paspalum (Norrmann, Quarín, and Burson, 1989) the role of intraspecific polyploidy, as a source of adaptive genetic variation or a cause of lost fitness, in an ecologically successful species remains an important problem for plant biology.

\section{LITERATURE CITED}

BennetT, A. W. 1873. The fertilization of grasses. Gardener's Chronicle 33: 362-400.

Church, G. L. 1929. Meiotic phenomena in certain grasses. II. Paniceae and Andropogoneae. Botanical Gazette (Chicago) 88: 63-94.

- 1940. Cytotaxonomic studies in the Gramineae Spartina, Andropogon and Panicum. American Journal of Botany 27: 263-71.

DE WET, J. M. J. 1980. Origins of polyploids.In W.H. Lewis [ed.],
Polyploidy, biological relevance. 3-16 Plenum Press, New York, NY.

Gould, F. W. 1956. Chromosome counts and cytotaxonomic notes on grasses in the tribe Andropogoneae. American Journal of Botany 43: 395-404.

. 1967. The genus Andropogon in the United States. Brittonia 19: $70-76$.

. 1968a. Chromosome numbers in Texas grasses. Canadian Journal of Botany 46: 1315-1325.

1968b. Variability in big bluestem Andropogon gerardii Vitman in deKalb and Ogle counties, Illinois. Southwestern Naturalist 65: 218-220.

JoNES, K. 1958. Cytotaxonomic studies in Holcus mollis I. The chromosome complex in Holcus mollis. L. New Phytologist 57: 191210.

KeELER, K. H. 1990. Distribution of polyploid polymorphism in big bluestem, Andropogon gerardii in the tallgrass prairie region. Genome 33: 95-100.

. 1992. Local polyploid variation in the native prairie grass Andropogon gerardii. American Journal of Botany 79: 1229-1232.

, AND B. KWANKIN. 1989. Polyploid polymorphism in prairie grasses. In J. H. Bock and Y. B. Linhart [eds.] Plant population biology, 99-128. Westview Press, Boulder, CO.

,,- P. W. Barnes, AND D. W. Galbraith. 1987. Polyploid polymorphism in Andropogon gerardii Vitman (Poaceae). Genome 29: $374-379$.

LAw, A., AND K. Anderson. 1940. The effect of selection and inbreeding on the growth of big bluestem (Andropogon furcatus, Muhl) Journal of the American Society of Agronomists 32: 931-943.

Lewis, W. H., Y. SudA, And B. MacBryde. 1967. Chromosome numbers of Claytonia virginica of the St. Louis Missouri area. Annals of the Missouri Botanical Garden 54: 147-152.

Löve, A., AND O. Solbrig. 1964. Chromosome numbers in Canadian species. In A. Löve and D. Löve [eds.]. I.O.B.P. chromosome number reports. I. Taxon 13: 100-110.

LumARET, R. 1988. Cytology, genetics and evolution in the genus Dactylis. CRC Critical Reviews of Plant Science 7: 55-91.

- AND E. BARRIENTOS. 1990. Phylogenetic relationships and gene flow between sympatric diploid and tetraploid plants of Dactylis glomerata (Gramineae). Plant Systematics and Evolution 169: 8196.

NiELSEN, E. L. 1939. Grass studies III. Additional somatic chromosome complements. American Journal of Botany 26: 366-372.

. 1944. Analysis of variation in Panicum virgatum. Journal of Agricultural Research 69: 327-353.

Norrmann, G. A. 1985. Estudios citogenéticos en las especies de $A n$ dropogon (Gramineae) de Argentina. Boletin de la Sociedad Argentina de Botánica 24:137-149.

. 1994. Citología y fertilidad en un híbrido interespecífico de Andropogon hypogynus $\times$ Andropogon lateralis. Actas XXV Con greso Argentino de Genetica. La Plata, Buenos Aires.

, AND C. L. QUARÍn. 1987. Permanent odd polyploidy in a grass (Andropogon ternatus). Genome 29: 340-344.

- AND —. 1991. Biología reproductiva en especies americanas de Andropogon (Gramineae). Boletin de la Sociedad Argentina de Botánica 27:85-90

$\longrightarrow$, AND B. L. Burson. 1989. Cytogenetics and reproductive behavior of different chromosome races in six Paspalum species. Journal of Heredity 80: 24-28.

Peters, L. C., AND L. V. NewEll. 1961. Hybridization between divergent types of big bluestem, Andropogon gerardi Vitman, and sand bluestem, Andropogon hallii Hack. Crop Science 1: 359-363.

Riley, R. D., AND K. P. Vogel. 1982. Chromosome numbers of released cultivars of switchgrass, indiangrass, big bluestem and sand bluestem. Crop Science 22: 1081-1083.

Risser, P. G., E. C. Birney, H. D. Blocker, S. W. May, W. J. Parton, AND J. A. WEINS. 1980. The true prairie ecosystem. US/IBP Synthesis Series Number 16. Hutchinson, Stroudsburg, PA.

Stebirns, G. L. 1971. Chromosomal evolution in higher plants. Addison-Wesley, Reading, MA.

Weaver, J. E. 1959. North American prairie. Johnsen, Lincoln, NE. , AND T. J. FitZPATRICK. 1934. The prairie. Ecological monographs 4: 109-295. 